J. clin. Path., 27, Suppl. (Roy. Coll. Path.), 7, 51-59

\title{
The neoplastic cell
}

\section{The effects of steroid hormones and carcinogens on the interaction of membranes with polysomes}

\author{
B. R. RABIN, CAROL A. BLYTH, DELMA DOHERTY, R. B. FREEDMAN, ANNE \\ ROOBOL, G. SUNSHINE, AND D. J. WILLIAMS
}

From the Department of Biochemistry, University College, London

Protein synthesis in the cell involves particulate elements called ribosomes which translate the information coded as specific nucleotide sequences in messenger RNA molecules into amino acid sequences of proteins (Lambourg and Zamecnik, 1960). Ribosomes are frequently found in the cell in the form of aggregates called polysomes. The ribosomes in a polysome are believed to be attached to a single messenger RNA molecule and simultaneously to translate the encoded information to give polypeptides with a specific amino acid sequence (Howell, Loeb, and Tomkins, 1964). The basic mechanisms of the control of protein synthesis at the level of translation are not well understood.

Polysomes can be observed by electron microscopy to exist in the cell in two distinctive forms -free polysomes, unattached to membranes and membrane-bound polysomes (Palade, 1955; Teng and Hamilton, 1967). The membrane-polysome complex constitutes the 'rough' membranes of the endoplasmic reticulum. A variety of other membranes also occur in the cell, including 'smooth' endoplasmic reticulum, characterized by the absence of bound polysomes.

Accumulating evidence indicates that free and bound polysomes are probably involved in the biosynthesis of different classes of proteins (Siekevitz and Palade, 1960; Campbell, 1970). For example, it is probable that proteins exported from the cell are biosynthesized by membrane-bound polysomes (Siekevitz and Palade, 1960) and this may also be true of other important classes of protein such as those whose biosynthesis is induced by steroid hormones (Cox and Mathias, 1969). Clearly the control of the interaction of polysomes with membranes could be of profound importance in dictating the tissue-specific pattern of protein biosynthesis which characterizes the processes of differentiation and development. Indeed there are indications that the ratio of free to bound polysomes is a function of the hormonal status of the organism (Cox and Mathias, 1969; Rancourt and Litwack, 1968; Mills and Topper, 1969; Maggi, Steggles, and Gahan, 1970). If chemical carcinogenesis is viewed as essentially an aberrant form of the processes of differentiation it is obviously important to investigate the effects of carcinogens on the interaction of membranes with polysomes.

The problem of investigating membrane-polysome interactions is considerably simplified by the fact that an enzyme present in the reticular membraneswhich we shall call the disulphide rearranging enzyme (or 'rearrangase') - has its activity masked when polysomes are bound to the membranes and its activity is fully exposed when the polysomes are removed. Thus the activity of 'rearrangase' provides a relatively simple means of measuring quantitatively polysome attachment to membranes in vitro. The enzyme is present in both 'rough' and 'smooth' membrane fractions, but the activity in rough membranes is zero and only appears when the polysomes are removed (Williams, Gurari, and Rabin, 1968). 'Rearrangase' catalyses a complex reaction of disulphide exchange and is probably involved in the terminal stages of protein biosynthesis (Goldberger, Epstein, and Anfinson, 1963).

Native bovine pancreatic ribonuclease contains four disulphide bonds. By reduction and reoxidation of the enzyme under denaturing conditions, it is possible to produce a protein in which the disulphide bonds are 'wrongly' paired and which is devoid of any catalytic action. If this 'randomly oxidized' material is used as substrate, the activity of 'rearrangase' can be measured by following the appearance of ribonuclease activity since the membrane-bound 'rearrangase' catalyses the 're-shuffling' of the sulphurs of the wrongly folded protein to give the native structure (Goldberger et al, 1963).

In fig 1 the specific activity of 'rearrangase' is plotted against the RNA/protein ratio of various 
membrane subfractions prepared by differential centrifugation techniques from male rat liver. Similar and parallel plots are obtained from other tissues of the rat (Williams and Rabin, 1969). The $\mathrm{RNA} /$ protein ratio is a measure of the number of ribosomes bound per unit weight of the membrane. The linear relationship is not surprising, since the various subfractions are composed of rough and smooth membrane components but in different ratios. Notice that the 'roughest' components are totally devoid of enzymic activity. If those fractions with a high RNA/protein ratio are dialysed against EDTA, which causes polysome dissociation from the membranes, and the specific activity of the separated membranes is determined, the values obtained approach that corresponding to the intersection of the line in fig 1 with the ordinate axis. The degranulated rough membranes have approximately the same specific activity as smooth membranes: the 'enzyme density' is the same for all membranes from a given tissue and the enzyme is uniquely coupled to the loci of polysome binding. It may indeed be located in the vicinity of the ribosome-binding site which would be a favourable location for the enzyme to operate in the terminal stages of protein biosynthesis using the newly formed nascent protein as substrate.

Figure 2 illustrates an experiment in which liver

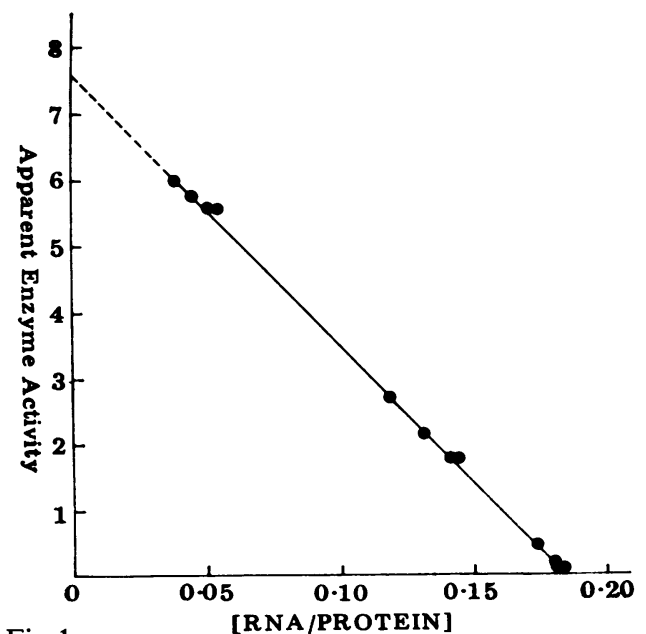

Fig 1 membranes were stripped of polysomes by EDTA treatment so as to uncover nearly all latent 'rearrangase' activity and the resultant degranulated membranes were incubated with fresh polysomes in the presence of magnesium ions. The 'rearrangase' activity falls to the initial low value of the original, mainly rough membranes as the polysomes reattach to the membranes. Notice that the experimental curve does not cross below that of the control of the unstripped membranes incubated with polysomes. Now the activity present in these unstripped membranes is due to the presence of smooth membranes and it is clear that although degranulated rough membranes will rebind polysomes, smooth membranes will not. This lack of interaction has been confirmed by using purified smooth membrane preparations. The reattachment of polysomes to stripped rough membranes has also been confirmed by measuring directly RNA bound to the membranes after separation of unbound polysomes by centrifugation (Williams and Rabin, 1969). Clearly smooth membranes are operationally different from degranulated rough membranes: the difference seems to be due to a component present in rough but absent in smooth reticulum as we shall see later.

The reattachment of polysomes to degranulated rough membranes is remarkably sex specific (fig 3 ). It can be seen that degranulated rough membranes

Fig 1 The relationship between apparent disulphide interchange activity (arbitrary units) and the RNA/protein ratio, for microsomal fractions derived from rat liver by differential centrifugation (assay methods as in Williams et al, 1968).

Fig 2 The binding of polysomes to 'polysome-depleted' membranes, monitored by the masking of disulphide interchange activity. Rough microsomal membranes were degranulated by EDTA (Williams et al, 1968; Williams and Rabin, 1969), isolated, and then incubated $(\sim 4 \mathrm{mg} / \mathrm{ml}$ protein) with excess free polysomes $(\sim 1 \mathrm{mg} / \mathrm{ml} \mathrm{RNA})$ at $25^{\circ} \mathrm{C}(\bigcirc)$. Untreated rough membranes were also incubated with free polysomes as a control $(O)$. 


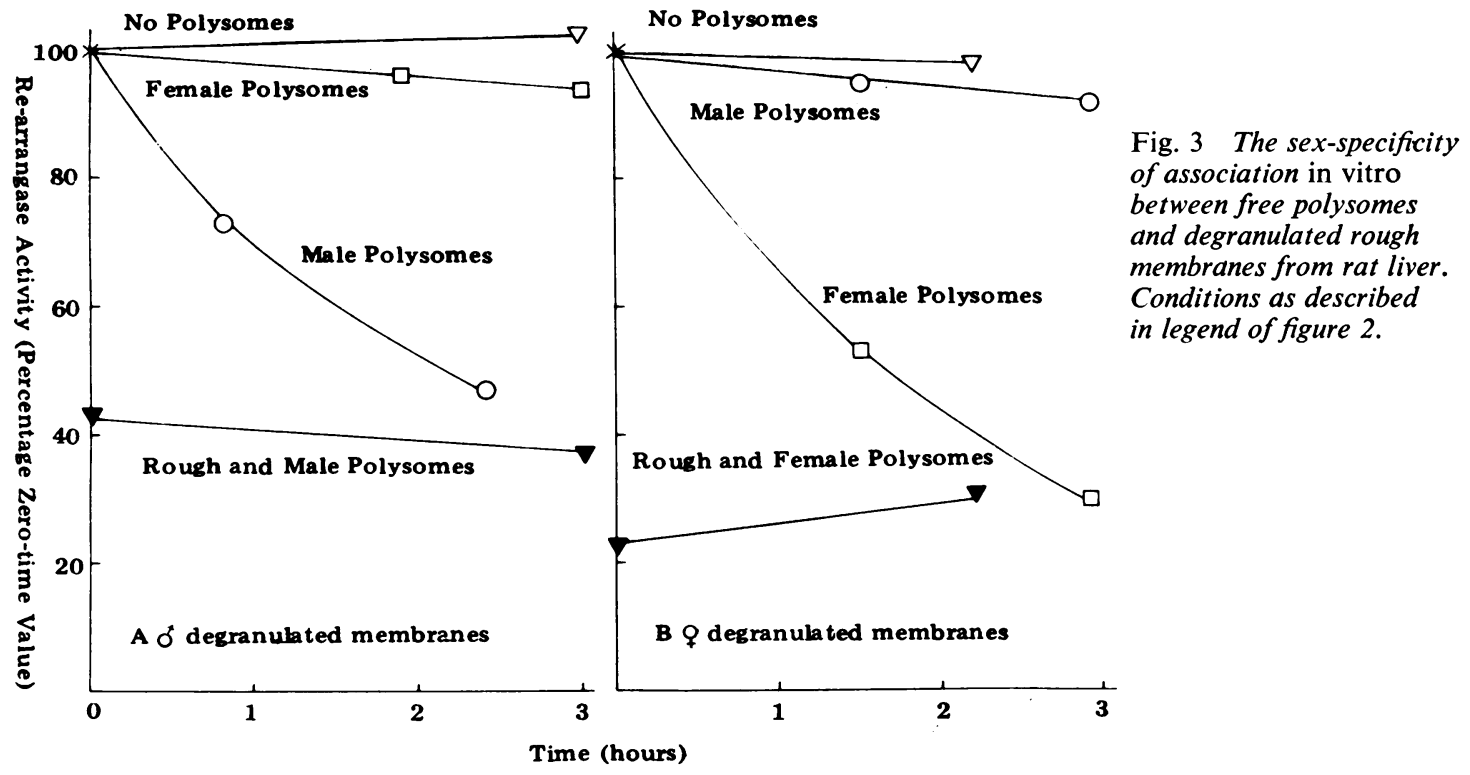

will re-bind polysomes from the same, but not the opposite sex. Before considering this sex specificity in detail we shall consider the nature of the differences between smooth and degranulated rough membranes. It is possible to prepare an ethyl acetate extract of male rough membranes which will activate both male and female smooth membranes to bind polysomes of either sex. A similar extract from male polysomes will promote the binding of female polysomes to female smooth membranes but not male polysomes to male smooth membranes. Analogous extracts from female polysomes promote the attachment of male polysomes to male membranes. These data are summarized in table $I$.
Although the presentation is qualitative, experimental determinations are actually very clear cut, and binding in the experimental systems seems to be almost an all-or-none phenomenon. The male polysomes contain a material which will activate the female but not the male system and vice versa. Male rough reticulum contains the components required to activate both the male and female systems. These unknown substances can be provided by the polysomes without extraction since a mixture of male plus female polysomes, but not the separate components, will bind to either male or female smooth membranes.

The above experiments strongly suggest that in

\begin{tabular}{llll}
\hline Smooth Membrane & Polysomes & Ethyl Acetate Extract & $\begin{array}{c}\text { Formation of Membrane-polysome } \\
\text { Complex }\end{array}$ \\
\hline Male & Male & None & Male polysomes \\
Male & Male & Female polysomes \\
Male & Male & Male rough membranes \\
Male & Male & None & - \\
Male & Female & None & - \\
Female & Female & Female polysomes \\
Female & Female & Male polysomes \\
Female & Female & Male rough membranes \\
Female & Female & None & - \\
Female & Male & None & - \\
Female & Male + female & None & - \\
Male & Male + female & -
\end{tabular}

Table I Interaction of polysomes with smooth membranes as measured by disulphide rearranging enzyme

Membranes (5-7 mg protein $/ \mathrm{ml}$ ) were incubated with polysomes (2-5 $\mathrm{mg}$ RNA per $\mathrm{ml}$ ) in the presence and absence of various 'ethyl acetate extracts'. The extracts were prepared by suspending the polysomes rough membranes in water $(3 \mathrm{ml})$ and extracting three times with $6 \mathrm{ml}$ portions of ice-cold ethyl acetate. The pooled extracts were evaporated to dryness, dissolved in $0.05 \mathrm{ml}$ dimethyl formamide and diluted with $0.15 \mathrm{ml}$ of $0 \cdot 25 \mathrm{M}$ sucrose in $50 \mathrm{mM}$ Tris-chloride containing $25 \mathrm{mM} \mathrm{KCL}$ and $5 \mathrm{mM} \mathrm{MgCl} 2$ (TKM). 


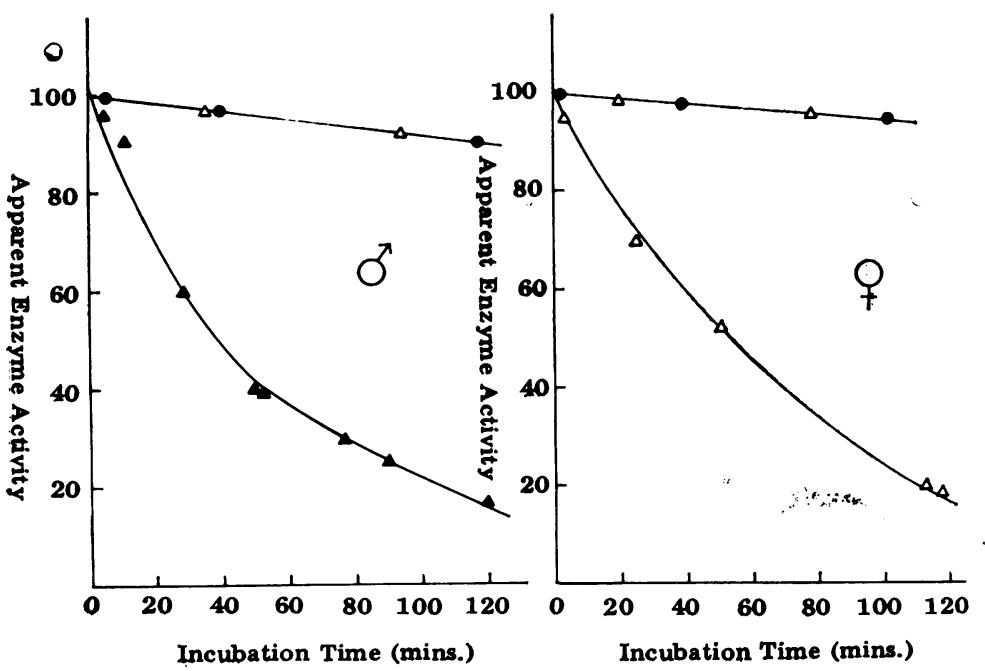

Fig 4 The sex-specific effects of steroid hormones in promoting association of free polysomes and smooth microsomal membranes in vitro. Incubations of steroids with male and female smooth microsomes and polysomes. No steroid present (O); in presence of $2 \mu \mathrm{g} \mathrm{ml}^{-1}$ oestradiol ( $\Delta)$; in presence of 2 $\mu \mathrm{gl}^{-1}$ testosterone $(\triangle)$. male rat liver, smooth membranes will not bind polysomes because there is a deficiency of a material which is soluble in organic solvents and present in female polysomes or male rough endoplasmic reticulum. In the female there would be an analogous deficiency, but of a different material which is present in male polysomes. One obvious possibility would be the involvement of the pair of sex hormones, with oestradiol being deficient in the male and testosterone deficient in the female. This would require that testosterone or oestradiol is present in male or female polysomes, respectively, as isolated. These hormones have, indeed, been previously implicated in the interaction of smooth membranes with polysomes (Rabin, Sunshine, and Williams, 1970; Sunshine, Williams, and Rabin, 1971) and some of the experimental evidence is presented in figure 4. It is clearly demonstrated in fig 4 that oestradiol promotes the binding of male polysomes to male smooth membranes. Testosterone is without any effect. The binding in the presence of oestradiol in vitro has been confirmed by electron microscopy (James, Rabin, and Williams, 1969) and it has been estimated, very approximately, that one molecule of steroid hormone is required per ribosome bound to the membrane. Figure 4 illustrates the situation in the female: the effects are totally opposite to the male. Testosterone promotes polysome binding, oestradiol is without effect. The concentrations of hormone required are again of the order of one molecule per bound ribosome. These experiments show very clear-cut differences between male and female animals, which could derive from sex specificity of steroid interactions with membranes and/or polysomes.
One, but by no means the only, possible explanation of the results is (1) that in both sexes oestradiol and testosterone are required to be simultaneously present to activate the membranes for polysome binding; (2) that polysomes and/or membranes of the female already contain oestradiol, or an equivalent material, and those of the male a substance with equivalent properties to testosterone. This explanation would, of course, be entirely consistent with the ability of the ethyl acetate extracts of polysomes to promote membrane-polysome interaction in the opposite sex. To shed further light on this problem some experiments were conducted to determine the steroid hormone requirements for the interaction of membranes with polysomes from the opposite sex. Some of these results are summarized in tables II and III. It can be seen that testosterone promotes the interaction of male membranes with female polysomes and oestradiol a similar interaction of female membranes with male polysomes.

It seems clear from the work described above that steroid hormones (or equivalent materials extracted from polysomes or membranes) are required for membrane-polysome interactions to occur. The requirements are sex-specific and are for oestradiol (or equivalent material extracted from female polysomes) in the male and testosterone (or equivalent material extracted from male polysomes) in the female. The crossed-sex experiments suggest there may also be a requirement for the other hormone, although this possibility cannot yet be tested experimentally in the interaction of membranes with polysomes from the same sex, because the male and female polysomes already contain, respectively, 


\begin{tabular}{lll}
\hline Polysome Sex & Added Steroid & $\begin{array}{l}\text { Formation of } \\
\text { Membrane-polysome } \\
\text { Complex }\end{array}$ \\
\hline Female & None & - \\
Female & Oestradiol & - \\
Female & Testosterone & + \\
Male & None & - \\
Male & Testosterone & - \\
Male & Oestradiol & + \\
\hline
\end{tabular}

Table II Steroid hormone requirements for the interaction of polysomes with female smooth membranes ${ }^{1}$

${ }^{1}$ Incubations of membranes and polysomes, and assay for complex formation as in table I

\begin{tabular}{lll}
\hline Polysome Sex & Added Steroid & $\begin{array}{l}\text { Formation of } \\
\text { Membrane-polysome } \\
\text { Complex }\end{array}$ \\
\hline Male & None & - \\
Male & Testosterone & - \\
Male & Oestradiol & - \\
Female & None & - \\
Female & Oestradiol & - \\
Female & Testosterone & + \\
\hline
\end{tabular}

Table III Steroid hormone requirements for the interaction of polysome with male smooth membranes ${ }^{1}$

${ }^{1}$ Incubations of membranes and polysomes, and assay for complex formation as in table I

substances equivalent to testosterone and oestradiol. It is certainly true to say that in all systems in which polysomes interact with membranes both hormones (or equivalent materials) are present. We are at present attempting to deplete polysomes of their hormone content to test whether both hormones are involved in the binding process.

Further relevant information has been obtained by direct binding studies of steroid hormones to membranes (Blyth, Freedman, and Rabin, 1971). Figure 5 shows the binding curves obtained for the interaction of oestradiol with male smooth and degranulated rough membranes. There are some quite profound differences between the two types of membrane. The smooth membranes have sites at which the hormone is bound very tightly (region A-B, we shall call these 'tight sites') and which can be saturated; at higher hormone concentration (region B-C) there is an almost linear partitioning of the hormone between the membranes and solution. At still higher hormone concentration (region C-D) a further set of hormone-binding sites comes into operation. Degranulated rough membranes do not possess sites in the regions A-B and C-D. We have evidence that binding in the region $C-D$ involves the microsomal hydroxylase complex, which is mainly located in smooth membranes. We shall consider only binding in the region A-B. The binding curves of the 'tight sites' only are shown in

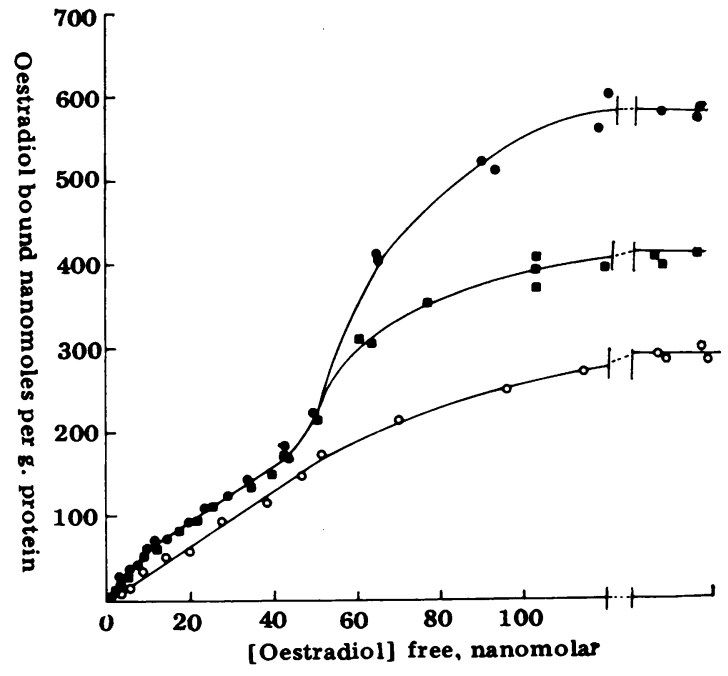

Fig 5 Direct titration of ${ }^{3} \mathrm{H}$-oestradiol with male rat liver microsomes. Methods as in Blyth et al (1971). Smooth microsomes ( $\square$ : EDTA-treated smooth microsomes (O); EDTA degranulated rough microsomes $(\bigcirc)$.

figures 6 and 7. They show the same remarkable sex specificity as the interaction of smooth membranes with polysomes from the same sex. It can be seen that male smooth membranes possess 'tight sites' for oestradiol and female membranes similar sites for testosterone. The sites are very specific since oestradiol and testosterone do not compete with each other for these 'tight sites'. Degranulated membranes from either sex apparently do not possess 'tight sites' for either hormone.

Degranulated membranes possess high affinity binding sites for oestradiol and testosterone in the male and female, respectively. These sites are not observed in titration experiments of the type described above because they are already occupied by the appropriate steroid (Blyth, Cooper, Roobol, and Rabin, 1972). It is presumably for this reason that degranulated membranes interact with ribosomes of the same sex without the necessity for the addition of a hormone.

We have also investigated the effects of a range of carcinogenic and other substances on the interaction of membranes with steroids and polysomes. Our earlier experiments showed that the hepatotoxin and carcinogen, aflatoxin $B_{1}$, will directly degranulate the rough endoplasmic reticulum by irreversible interaction with the membranes (Williams and Rabin, 1969). Figure 8 shows the degranulating effect for both male and female 


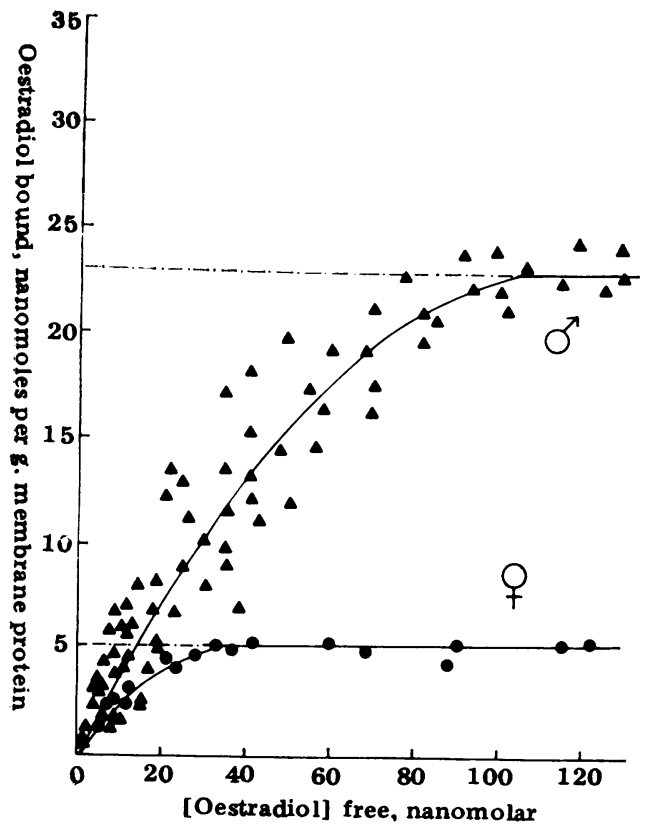

Fig 6

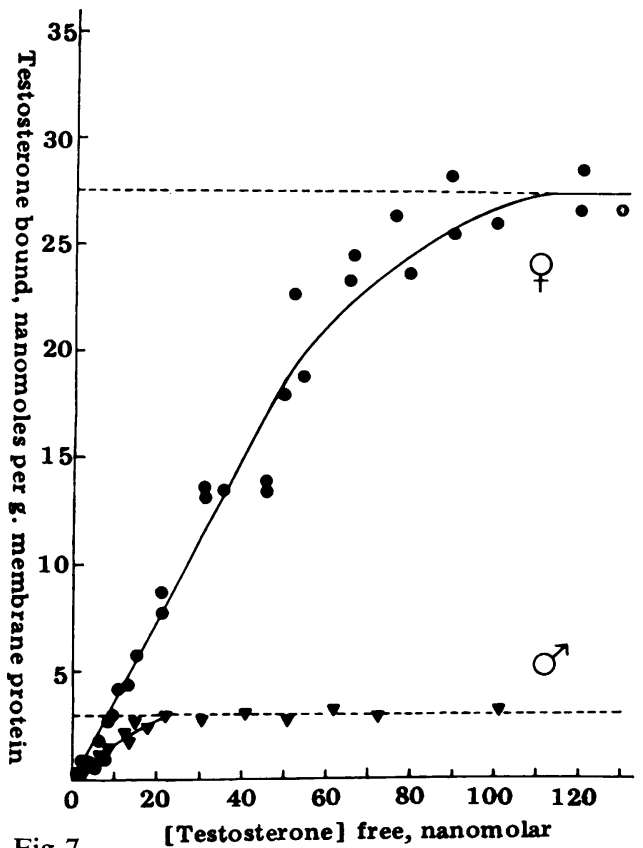

Fig 7

smooth microsomes.

Fig 7 Titration of the 'tight' binding sites (Blyth et al, 1971) for testosterone in male ( $\boldsymbol{\nabla})$ and female ( $)$ rat liver smooth microsomes.

membranes as measured by assaying the 'rearrangase' enzyme. The results have been confirmed by direct measurements of RNA attached to the membranes (Williams and Rabin, 1969). If the carcinogen is acting by interfering with a site on the membrane which binds steroid hormones, then it is to be expected that the appropriate hormone will protect the membrane against the degranulating effects of the carcinogen. This is indeed observed, as shown in fig 8 and, again, the protection is sex specific: oestradiol protects male and testosterone female membranes. Aflatoxin $B_{1}$ also destroys the
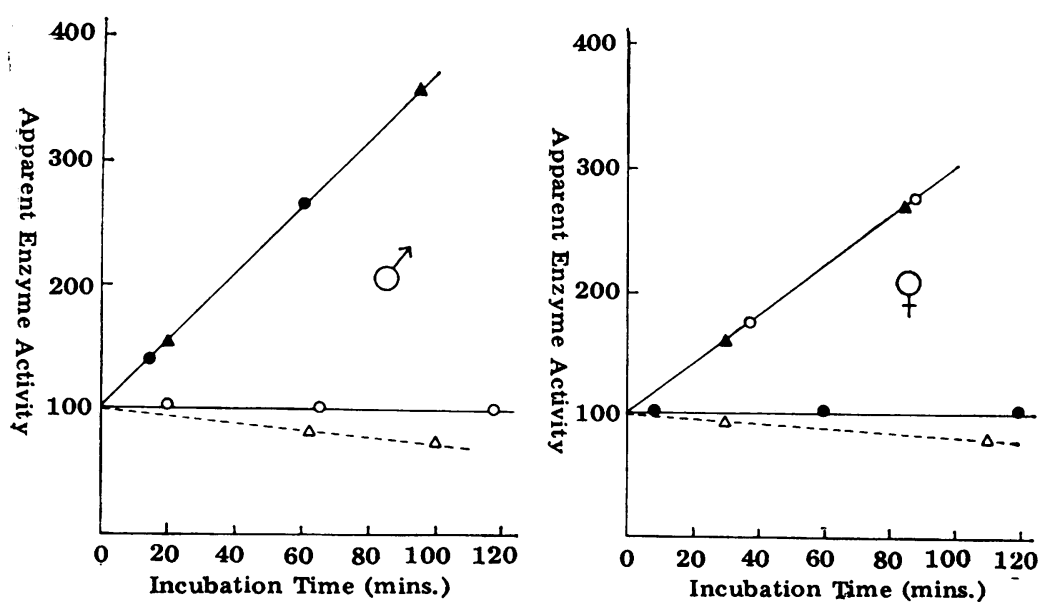

Fig 8 The effects of steroid hormones on the reaction of aflatoxin $B_{1}$ with rough microsomes from male and female rat liver. Membranes at $\sim 4 \mathrm{mg} / \mathrm{ml}$ protein. Control incubation $(\triangle)$; incubation with aflatoxin $B_{1}(40 \mu \mathrm{g} / \mathrm{ml})$ alone $(\Delta)$; incubation with aflatoxin $B_{1}$ and oestradiol (10 $\mu \mathrm{g} / \mathrm{ml})(\mathrm{O})$; incubation with aflatoxin $B_{1}$ and testosterone $(10 \mu \mathrm{g} / \mathrm{ml})(\mathrm{O})$. 
ability of smooth membranes to interact with polysomes in the presence of the appropriate hormone. These effects of aflatoxin $B_{1}$ are also observed by feeding experiments in vivo. The smooth membranes from male rats fed on a diet containing $5 \mathrm{ppm}$ aflatoxin $B_{1}$ have totally lost their ability to bind polysomes in the presence of oestradiol in just two days. The carcinogen destroys the ability of smooth membranes to react with polysomes much more rapidly than it degranulates rough membranes.

Binding studies have demonstrated that aflatoxin $B_{1}$ destroys the tight binding sites for steroid
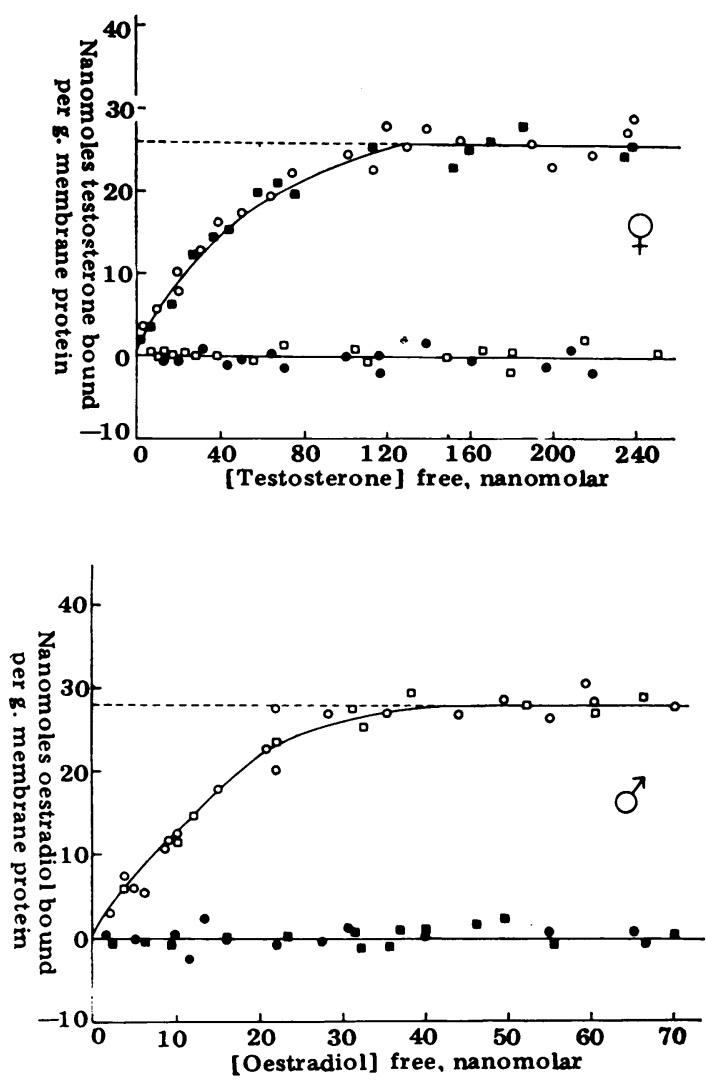

Fig. 9 The effect of aflatoxin $B_{1}$ on 'tight' steroidbinding sites Blyth et al, 1971) of smooth microsomes from rat liver. Titration of male microsomes with ${ }^{3} \mathrm{H}$ oestradiol. Titration of female microsomes with ${ }^{14} \mathrm{C}$ testosterone. For both graphs: untreated membranes (O); membranes ( $3 \mathrm{mg} / \mathrm{ml}$ protein) incubated at $25^{\circ} \mathrm{C}$ with aflatoxin $B^{3}(3 \mu M)$ for 20 hours before titration (O); membranes incubated with aflatoxin, as above, in presence of oestradiol (375 nM) $(\square)$; membranes incubated with aflatoxin, as above, in presence of testosterone $(375 n M)(\square)$. hormones on smooth membranes and some of the relevant experiments are illustrated in figure 9. It can be seen that oestradiol, but not testosterone, protects the tight oestradiol sites on male smooth membranes. Similarly, testosterone, but not oestradiol, protects the sites for this hormone on female membranes.

To summarize, the data presented show that oestradiol and testosterone respectively activated male and female smooth membranes to bind polysomes. There are specific 'tight sites' for oestradiol on male and for testosterone on female smooth membranes. These sites are destroyed irreversibly by aflatoxin $B_{1}$. These hormones, or equivalent substances, are already present in rough reticulum. Aflatoxin $B_{1}$ causes the irreversible displacement of polysomes from rough membranes and the evidence is consistent with the blocking of a specific hormone site. The steroid sites on both rough and smooth membrane can be specifically protected by the hormone involved against destruction by the carcinogen.

A number of other carcinogenic substances have shown to produce the same effects as aflatoxin $\mathbf{B}_{1}$. Table IV shows the relative degranulation, measured as increase in 'rearrangase' enzyme activity, caused by incubation of microsomal membranes, mainly rough but containing some smooth, with various carcinogenic compounds and some innocuous relatives, in the presence of $1 \mathrm{mM}$ NADPH (and postmitochondrial supernatant). Clearly some of the compounds do indeed cause degranulation and in

\begin{tabular}{|c|c|c|}
\hline Substance Tested & $\begin{array}{l}\text { Rate of Enzyme } \\
\text { Activation }^{2}\end{array}$ & Carcinogenicity \\
\hline $\begin{array}{l}\text { Naphthalene } \\
\text { 2-Naphthylamine } \\
\text { Anthracene } \\
\text { 2,7-Diaminofluorene } \\
\text { 1,2-Benzanthracene } \\
\text { 1,2-Benzanthraquinone } \\
\text { 2-Aminochrysene } \\
\text { 6-Aminochrysene } \\
\text { 3-Aminopyrene } \\
\text { 3,4-Benzpyrene } \\
\text { Benzo(b)chrysene } \\
\text { 3,4,8,9-Dibenzypyrene } \\
\text { Carbon tetrachloride } \\
\left(15 \mu \mathrm{g} l^{2-}\right) \\
\text { Aflatoxin } \text { B }^{-1}\left(10 \mu \mathrm{ml}^{-1}\right)^{3}\end{array}$ & $\begin{array}{l}0 \\
0-3 \\
0 \\
8 \\
5 \\
8 \\
8 \\
0 \\
9 \\
20 \\
0 \\
13 \\
8 \\
10\end{array}$ & $\begin{array}{l}\text { Nil } \\
\pm \\
\text { Nil } \\
+ \\
+ \\
+ \\
+ \\
\text { Nil } \\
+ \\
+ \\
\text { Nil } \\
+ \\
+ \\
+ \\
+\end{array}$ \\
\hline
\end{tabular}

Table IV Rate of increase of apparent disulphide interchange enzyme activity of microsomal membranes from rat liver on incubation with the substances indicated in the presence of NADPH

${ }^{1}$ Incubated at $20^{\circ} \mathrm{C}$ with microsomal membranes $(\sim 10 \mathrm{mg}$ protein $\mathrm{ml}^{-1}$ ) at a concentration of $5 \mu \mathrm{g} \mathrm{ml}^{-1}$ (unless otherwise stated) in the presence of $1 \mathrm{mM}$ NADPH, $50 \mathrm{mM}$ tris, $25 \mathrm{mM} \mathrm{KCl,} 5 \mathrm{mM} \mathrm{MgCl}$ and $250 \mathrm{mM}$ sucrose, at $\mathrm{pH}$ 7.3. Postmicrosomal supernatant was added to $10 \%$ final volume.

'Percentage of total enzyme activity released per hour.

Absence of NADPH 
this series correlation with carcinogenicity is complete. The NADPH is an absolute requirement in each case. The term 'carcinogenicity' as applied to the active compounds in the table needs some definition. A compound is deemed 'carcinogenic' if it can cause tumour formation in any tissue in the rat; clearly not all of the compounds listed in the table are hepatocarcinogens.

To confirm that the apparent enzyme activation was the result of degranulation, a selection of the compounds, listed in table IV, were incubated with microsomal membranes in the presence of NADPH. The incubates were then centrifuged at $120000 \mathrm{~g}$ for four hours over a layer of $2 \cdot 0 \mathrm{M}$ sucrose to separate membranes from unbound ribosomes. The difference in RNA/protein ratios of the membranes, floating on the $2.0 \mathrm{M}$ sucrose layer, compared with that of untreated membrane gives a direct measure, in terms of RNA, of the degranulation. Table V summarizes the results obtained which clearly correlate well with the results obtained indirectly in table IV. The carcinogen-pretreated membranes would not bind added fresh ribosomes in the presence of oestradiol $\left(1 \mu \mathrm{g} \mathrm{ml}^{-1}\right)$ even after extensive washing, so that not only is the degranulation operationally irreversible, but all of the potential ribosome-binding sites on the original smooth membranes are destroyed as well.

The mechanism of the carcinogen activation and subsequent degranulation is not yet clear, but studies with various modifiers of the microsomal hydroxylase complex, summarized in table VI, suggest the involvement of the cytochrome P450flavoprotein enzyme system present in microsomal membranes (Orrenius, 1965). The absolute requirement for NADPH, the partial inhibition by alternative substrates, and the complete inhibition by $\mathrm{CO}$ and the P450 specific inhibitor-SKF 525A-all point to this conclusion. Similarly the complete inhibition of the overall degranulation by low concentrations of oestradiol strongly suggest that it is thesteroid-specific site, responsible for maintaining

\begin{tabular}{|c|c|c|c|}
\hline \multirow[t]{2}{*}{ Substance Tested ${ }^{1}$} & \multicolumn{3}{|c|}{$\begin{array}{l}\text { RNA Removed from Membrane } \\
(\% \text { control })\end{array}$} \\
\hline & $\begin{array}{l}\text { Measured } \\
\text { Directly }\end{array}$ & Calculated $^{2}$ & \\
\hline Naphthalene & 0 & 0 & Nil \\
\hline Anthracene & 0 & $\mathbf{0}$ & Nil \\
\hline 2,7-Diaminofluorene & 30 & 30 & + \\
\hline 2-Aminochrysene & 30 & 30 & + \\
\hline 6-Aminochrysene & 0 & 0 & $\mathrm{Nil}$ \\
\hline 3-Aminopyrene & 27 & 35 & + \\
\hline 3,4-Benzpyrene & 25 & 40 & + \\
\hline $\begin{array}{l}\text { Carbon tetrachloride } \\
\left(15 \mu \mathrm{g} \mathrm{m}^{-1}\right)\end{array}$ & 35 & 30 & + \\
\hline
\end{tabular}

Table V Degranulation of rough surfaced microsomal membranes from male rat liver caused by incubation with the substance indicated in the presence of NADPH

${ }^{1}$ Mixture of rough and smooth membranes incubated at $20^{\circ} \mathrm{C}$ for 2 hours as described in footnote to table IV, and centrifuged over a layer of $2.0 \mathrm{M}$ sucrose for 4 hours, $120000 \mathrm{~g}$ to remove unbound ribosomes.

${ }^{2}$ Corresponding values calculated from the data summarized in table IV.

membrane-polysome complex integrity; this is attacked by the activated 'carcinogen'.

The phenomena observed in vitro for aflatoxin are also observed in vivo. Substantial degranulation of rough reticular membranes occurs on feeding the toxin at a level of $5 \mathrm{ppm}$ for nine weeks. All of the potential ribosome-binding sites on the smooth membranes are destroyed on feeding the toxin for just two days at the same level. In vivo experiments with another carcinogen, ethionine (Williams, Rabin, and Kisilevsky, 1972), also showed substantial degranulation of rough reticular membranes. Unlike aflatoxin, ethionine produces a lesion in the ribosomes which makes them incapable of interacting with membranes from control animals. The membranes from ethionine-treated animals still retain ribosomebinding sites and will interact, under appropriate conditions, with ribosomes from control animals. Ethionine is the only compound discovered so far in which the ribosomes, rather than the membranes, are damaged by a carcinogen.

\begin{tabular}{|c|c|c|c|}
\hline \multirow[t]{2}{*}{ Incubation } & \multicolumn{3}{|c|}{ Rates of Degranulation ${ }^{2}$} \\
\hline & Benzanthraquinone & Dibenzpyrene & 2-Aminochrysene \\
\hline $\begin{array}{l}\text { Control } \\
\text { - NADPH } \\
\text { + Naphthalene }\left(10 \mu \mathrm{g} \mathrm{ml}^{-1}\right) \\
\text { + CO } \\
\text { + SKF 525A }(1 \mathrm{mM}) \\
\text { + Oestradiol }\left(1 \mu \mathrm{gl}^{-1}\right) \\
\text { + Testosterone }\left(1 \mu \mathrm{g} \mathrm{ml}^{-1}\right)\end{array}$ & $\begin{array}{l}8 \\
0 \\
2 \\
0 \\
0 \\
0 \cdot 5 \\
\text { Not tested }\end{array}$ & $\begin{array}{r}13 \\
0 \\
2 \\
0 \\
0 \\
0 \\
9\end{array}$ & $\begin{array}{l}8 \\
0 \\
2 \\
\text { Not tested } \\
0 \\
0 \cdot 5 \\
\text { Not tested }\end{array}$ \\
\hline
\end{tabular}

Table VI effect of various substances on the carcinogen-induced degranulation of microsomal membranes from male rat liver

${ }^{1}$ Conditions exactly as described for table IV except additions where indicated.

${ }^{2}$ Measured as the rate of increase of apparent disulphide interchange enzyme activity. 
The importance of this type of interaction in the transformation of tissues in vivo is clearly impossible to evaluate at the present time but such an initial interaction in vivo is certainly consistent with the frequent reports of rough endoplasmic membrane degranulation (Baglio and Farber, 1965; Svoboda and Higginson, 1968; Flaks, 1970) and binding of carcinogens to cytoplasmic and microsomal protein (Miller and Miller, 1952; Wiest and Heidelberger, 1953; Hultin, 1956) during chemical tumorigenesis.

This article is an updated version of an article in Proceedings of the Third International Symposium on Endocrinology (1971). We are grateful to the Editor of this Symposium and William Heinemann Medical Books Ltd for permission to use this material.

We are grateful to the Cancer Research Campaign, Nuffield Foundation, and Medical Research Council for grants in support of this work. We are also grateful to the Science Research Council and the Salters Company for personal grants to C.A.B. and R.B.F.

\section{References}

Baglio, C. M., and Farber, E. (1965). Correspondence between ribosome aggregation patterns in rat liver homogenates and in electron micrographs following administration of ethionine. J. molec. Biol., 12, 466-467.

Blyth, C. A., Cooper, M. B., Roobol, A., and Rabin, B. R. (1972). The binding of steroid hormones to degranulated microsomes from rat liver endoplasmic reticulum. Europ. J. Biochem., 29, 293-300.

Blyth, C. A., Freedman, R. B., and Rabin, B. R. (1971). Sex specific binding of steroid hormones to microsomal membranes of rat liver. Nature [new Biol.], 230, 137-139.

Campbell, P. N. (1970). Functions of polyribosomes attached to membranes of animal cells. FEBS Letters, 7, 1-7.

Cox, R. F., and Mathias, A. P. (1969). Cytoplasmic effects of cortisol in liver. Biochem. J., 115, 777-787.

Flaks, B. (1970). Changes in the fine structure of rat hepatocytes during the early phases of chronic 2-acetylaminofluorene intoxication. Chem. biol. Interact., 2, 129-150.

Goldberger, R. F., Epstein, C. J., and Anfinson, C. B. (1963). Acceleration of reactivation of reduced bovine pancreatic ribonuclease by a microsomal system from rat liver. J. biol. Chem., 238, 628-635.

Howell, R. R., Loeb, J. N., and Tomkins, E. M. (1964). Characterisation of ribosomal aggregates isolated from liver. Proc. nat. Acad. Sci. (Wash.), 52, 1241-1248.
Hultin, T. (1956). The distribution of protein-bound azo dye in subfractions of liver cytoplasm fractions. Exp. Cell. Res., 10, 697-703.

James, D. W., Rabin, B. R., and Williams, D. J. (1969), Role of steroid hormones in the interaction of polysomes with endoplasmic reticulum. Nature (Lond.), 224, 371-372.

Lambourg, M. R., and Zamecnik, P. C. (1960). Amino acid incorporation into protein by extracts of $E$. Coli. Biochim. biophys. Acta (Amst.), 42, 206-211.

Maggi, V., Steggles, A. W., and Gahan, P. B. (1970). Effects of castration and of oestradiol treatment on the subcellular structure of the mouse seminal vesicles, with particular reference to the function of the Golgi apparatus and the lysosomes. Histochem. J., 2, 381-393.

Miller, E. C., and Miller, J. A. (1952). In vivo combinations between carcinogens and tissue constituents and their possible role in carcinogenesis. Cancer Res., 12, 547-556.

Mills, E. S., and Topper, Y. J. (1969). Mammary alveolar epithelial cells: effect of hydrocortisone on ultrastructure. Science, $\mathbf{1 6 5}$ 1127-1128.

Orrenius, S. (1965). On the mechanism of drug hydroxylation in rat liver microsomes. J. Cell. Biol., 26, 713-723.

Palade, G. E. (1955). A small particulate component of the cytoplasm. J. biophys. biochem. Cytol., 1, 59-68.

Rabin, B. R., Sunshine, G. H., and Williams, D. J. (1970). The masking of a membrane bound enzyme catalysing disulphide interchange by polysomes: effects of steroid hormones and aflatoxin $B_{1}$ on the system. Biochem. Soc. Symp., 31, 203-215.

Rancourt, M. W., and Litwack, G. (1968). Electron microscopic observations of the early effects of cortisol on the liver cell of the adrenalectomized rat. Exp. Cell Res., 51, 413-422.

Siekevitz, P., and Palade, G. E. (1960). A cytochemical study on the pancreas of the guinea pig. V. In vivo incorporation of leucine$1-C^{14}$ into the chymotrypsinogen of various cell fractions. J. biophys. biochem. Cytol., 7, 619-630.

Sunshine, G. H., Williams, D. J., and Rabin, B. R. (1971). Role for steroid kormones in the interaction of ribosomes with the endoplasmic membranes of rat liver. Nature [new Biol.], 230, 133-136.

Svoboda, D., and Higginson, J. (1968). A comparison of ultrastructural changes in rat liver due to chemical carcinogens. Cancer Res., 28, 1703-1733.

Teng, C. S., and Hamilton, T. H. (1967). Regulation of polyribosome formation and protein synthesis in the uterus. Biochem. J., 105, 1091-1099.

Wiest, W. G., and Heidelberger, C. (1953). The interaction of carcinogenic hydrocarbons with tissue constituents. II. 1,2,5,6dibenzanthracene-9,10-C $\mathrm{C}^{14}$ in skin. Cancer Res., 13, 250-254.

Williams, D. J., Gurari, D., and Rabin, B. R. (1968). The effects of ribosomes on the activity of a membrane bound enzyme catalysing thioldisulphide interchange. FEBS Letters, 2, 133135.

Williams, D. J., and Rabin, B. R. (1969). The effects of aflatoxin $\mathbf{B}_{1}$ and steroid hormones on polysome binding to microsomal membranes as measured by the activity of an enzyme catalysing disulphide interchange. FEBS Letters, 4, 103-107.

Williams, D. J., Rabin, B. R., and Kisilevsky, R. (1972). Endoplasmic membrane degranulation in vivo as a result of ethionineintoxication. FEBS Letters, 26, 245-248. 